\title{
Posttraumatic stress symptoms, dissociation, and alexithymia in an Italian sample of flood victims
}

\author{
This article was published in the following Dove Press journal: \\ Neuropsychiatric Disease and Treatment \\ 28 November 2014 \\ Number of times this article has been viewed
}

\author{
Giuseppe Craparo' \\ Alessio Gori ${ }^{2}$ \\ Elvira Mazzola' \\ Irene Petruccelli' \\ Monica Pellerone' \\ Giuseppe Rotondo3 \\ 'Faculty of Human and Social Sciences, \\ Kore University of Enna, Enna, \\ Italy; ${ }^{2}$ Department of Psychology, \\ University of Florence, Florence, Italy; \\ ${ }^{3}$ Department of Psychology, Unit of \\ Psychotraumatology, San Raffaele \\ Giglio Hospital of Cefalù, Cefalù, Italy
}

Correspondence: Giuseppe Craparo Faculty of Human and Social Sciences, Kore University of Enna, via Cittadella Universitaria, 94100 Enna, Italy.

Tel +390935 536536

Email giuseppe.craparo@unikore.it
Background: Several studies have demonstrated a significant association between dissociation and posttraumatic symptoms. A dissociative reaction during a traumatic event may seem to predict the later development of posttraumatic stress symptoms. Moreover, several researchers also observed an alexithymic condition in a variety of traumatized samples.

Methods: A total of 287 flood victims ( $\operatorname{men}=159,55.4 \%$; women $=128,44.6 \%$ ) with an age range of $17-21$ years ( mean $=18.33$; standard deviation $=0.68$ ) completed the following: Impact of Event Scale-Revised, Dissociative Experiences Scale II, Twenty-Item Toronto Alexithymia Scale, and Peritraumatic Dissociative Experiences Questionnaire.

Results: We found significant correlations among all variables. Linear regression showed that peritraumatic dissociation plays a mediator role between alexithymia, dissociation, and posttraumatic stress symptoms.

Conclusion: Our results seem to confirm the significant roles of both dissociation and alexithymia for the development of posttraumatic symptoms.

Keywords: peritraumatic dissociation, posttraumatic symptoms, PTSD

\section{Introduction}

Various traumatic experiences, such as a hurricane, earthquake, or traffic accident, may lead to the development of posttraumatic stress (PTS) syndromes. Several studies have recognized the significant role of pathological dissociation in the development of posttraumatic symptoms in traumatized individuals. For example, a meta-analysis performed by Lensvelt-Mulders et $\mathrm{al}^{1}$ confirmed the existence of a positive relation between peritraumatic dissociation and PTS later in life, with an effect size of 0.401 . According to these authors, although

This outcome suggests that experiencing dissociation during or shortly after a potentially traumatizing event increases the probability of PTS later in life, this should not be interpreted as proof for a causal relationship. ${ }^{1}$

On the contrary, Murray et $\mathrm{al}^{2}$ in investigating the relation between dissociative symptoms before, during, and after a trauma in two samples of 27 and 176 road traffic accident survivors found that persistent dissociation was a significant predictor of PTS symptoms. This controversial fact is complicated by those who maintain that dissociative reaction to an acute and severe traumatic event is related to alexithymia. ${ }^{3,4}$ For example, Monson et $\mathrm{al}^{5}$ in a total of 85 participants diagnosed with military-related posttraumatic stress disorder (PTSD), found that negative affectivity and alexithymic externally oriented thinking predicted PTSD symptoms.

The aim of our study was to evaluate interrelations among posttraumatic symptoms, alexithymia, dissociation, and peritraumatic dissociation in a sample of flood victims. 
Another aim was to investigate predictors of posttraumatic symptoms measured with the Impact of Event Scale-Revised (IES-R).

\section{Methods}

\section{Participants and procedure}

There were 287 participants $($ men $=159,55.4 \%$; women $=128$, $44.6 \%$ ) with an age range of 17-21 years (mean $=18.33$; standard deviation $[\mathrm{SD}]=0.68)$. The mean age of men was 18.47 years $(\mathrm{SD}=0.68)$, and that of women was 18.14 years $(\mathrm{SD}=0.64)$; mean ages were statistically different $(t=4.253$; $d f=285, P<0.001)$.

We randomly recruited a group of Italian victims of natural disaster (floods and mudslides) in 2009 in the city of Messina (Sicily, Italy). Self-reports were administered 27 months after the natural catastrophe.

\section{Measures}

\section{Dissociative Experiences Scale II}

The Dissociative Experiences Scale II (DES-II) is a 28-item self-report measure of psychological dissociation that is designed to be used as a screening instrument for dissociative disorders and to help determine the contribution of dissociation to psychiatric disorders. It has demonstrated good psychometric properties, such as adequate split-half reliability and test-retest reliability, as well as good convergent and discriminant validity. ${ }^{6}$ The Italian translation (Schimmenti et al, unpublished data, 2011) of the DES-II showed good internal consistency, good test-retest reliability, and good convergent validity in a mixed clinical and nonclinical sample. The Italian version of the DES-II showed good internal consistency $(\alpha=0.85)$.

\section{Twenty-Item Toronto Alexithymia Scale}

The Twenty-Item Toronto Alexithymia Scale (TAS-20) is a 20 -item self-report measure. Items are rated on a five-point Likert scale ranging from 1 (strongly disagree) to 5 (strongly agree). The TAS-20 is composed of three factors: 1) difficulty modulating and identifying feelings (DIF); 2) difficulty describing one's feelings to others (DDF); and 3) externally oriented thinking (EOT). Cutoff scores are as follows: $\leq 50=$ no alexithymia, $51-60=$ borderline alexithymia, and $\geq 61=$ alexithymia. $^{7}$ The Italian version ${ }^{8}$ of the TAS-20 has good internal consistency $(\alpha=0.81)$.

\section{Impact of Event Scale - Revised}

The Impact of Event Scale - Revised (IES-R) is a 22-item self-report used to assess the presence of posttraumatic syndromes. Items are rated on a five-point Likert scale ranging from 0 (not at all) to 4 (extremely). This scale is composed of three subscales: avoidance, intrusion, and hyperarousal. ${ }^{9}$ The Italian version ${ }^{10}$ of the IES-R presents good internal consistency (intrusion, $\alpha=0.78$; avoidance, $\alpha=0.72$; and hyperarousal, $\alpha=0.83$ ).

\section{Peritraumatic Dissociative Experiences Questionnaire}

The Peritraumatic Dissociative Experiences Questionnaire (PDEQ) is a ten-item self-report used to assess the presence of dissociative symptoms during or immediately after a traumatic event. Items are rated on a five-point Likert scale ranging from 1 (not at all true) to 5 (extremely true). ${ }^{11}$ The Italian version (Craparo et al, unpublished data, 2013) of the PDEQ presents good internal consistency $(\alpha=0.81)$.

\section{Data analysis}

Descriptive statistics were calculated for all participants. We used Pearson's coefficients to assess correlations among all the variables in our study. Linear regressions were calculated to examine predictors of posttraumatic syndromes. All analyses were conducted with SPSS 19.0.

\section{Results}

Table 1 shows mean scores and SDs for all variables.

The Pearson's correlation coefficients among variables showed significant associations of IES-R and its three factors (avoidance, intrusion, hyperarousal) with TAS-20 and its two factors (DIF and DDF), PDEQ, and DES-II (Table 2).

From the linear regression results (stepwise method) performed with IES-R as a dependent variable, PDEQ was found to explain $43.9 \%$ of the IES-R total score variance (beta unstandardized coefficient $[\mathrm{B}]=1.31$, standard error $[\mathrm{SE}]=0.088, \beta=0.664, t=14.95, P<0.001)$.

Table I Mean score and SD for all variables

\begin{tabular}{lll}
\hline & Mean & SD \\
\hline TAS-20 & 48.1 & 11.6 \\
DIF & 15.8 & 6.39 \\
DDF & 13.1 & 4.80 \\
EOT & 19.4 & 5.14 \\
PDEQ & 21.3 & 7.91 \\
DES-II & 25.5 & 17.8 \\
IES-R & 23.0 & 15.7 \\
A/IES-R & 7.9 & 6.15 \\
I/IES-R & 8.4 & 5.67 \\
H/IES-R & 6.8 & 5.93 \\
\hline
\end{tabular}

Abbreviations: A/IES-R, avoidance subscale of IES-R; DDF, difficulty describing feelings; DES-II, Dissociative Experiences Scale II; DIF, difficulty identifying feelings; EOT, externally oriented thinking; IES-R, Impact of Event Scale - Revised; $H / I E S-R$, hyperarousal subscale of IES-R; I/IES-R, intrusion subscale of IES-R; PDEQ, Peritraumatic Dissociative Experiences Questionnaire; SD, standard deviation; TAS-20, Twenty-Item Toronto Alexithymia Scale. 
Table 2 Pearson's correlation coefficients

\begin{tabular}{|c|c|c|c|c|c|c|c|c|c|c|}
\hline & IES-R & A/IES-R & I/IES-R & H/IES-R & DES-II & PDEQ & TAS-20 & DIF & DDF & $\overline{\text { EOT }}$ \\
\hline IES-R & - & & & & & & & & & \\
\hline A/IES-R & $0.884^{* *}$ & - & & & & & & & & \\
\hline I/IES-R & $0.899 * *$ & $0.707 * *$ & - & & & & & & & \\
\hline $\mathrm{H} / \mathrm{IES}-\mathrm{R}$ & $0.883 * *$ & $0.693 * *$ & $0.744 * *$ & - & & & & & & \\
\hline DES-II & $0.357^{* *}$ & $0.325 * *$ & $0.319 * *$ & 0.276 ** & - & & & & & \\
\hline PDEQ & $0.668^{* *}$ & $0.577^{* *}$ & $0.627^{* *}$ & $0.635^{* *}$ & $0.399 * *$ & - & & & & \\
\hline TAS-20 & $0.429 * *$ & $0.384 * *$ & $0.370 * *$ & $0.408 * *$ & $0.410 * *$ & $0.424^{* *}$ & - & & & \\
\hline DIF & $0.421 * *$ & $0.355 * *$ & $0.384 * *$ & $0.388 * *$ & $0.419 * *$ & $0.46 I^{* *}$ & $0.776 * *$ & - & & \\
\hline DDF & 0.330 ** & $0.265^{* *}$ & $0.289 * *$ & $0.307^{* *}$ & $0.226 * *$ & $0.369 * *$ & $0.712 * *$ & $0.567^{* *}$ & - & \\
\hline EOT & $0.139 *$ & $0.172^{* *}$ & 0.086 & $0.165^{* *}$ & $0.146 *$ & 0.066 & $0.467 * *$ & 0.035 & 0.034 & - \\
\hline
\end{tabular}

Notes: **Correlation is significant at the 0.01 level (two-tailed). *Correlation is significant at the 0.05 level (two-tailed).

Abbreviations: A/IES-R, avoidance subscale of IES-R; DDF, difficulty describing feelings; DES-II, Dissociative Experiences Scale II; DIF, difficulty identifying feelings; EOT, externally oriented thinking; IES-R, Impact of Event Scale - Revised; H/IES-R, hyperarousal subscale of IES-R; I/IES-R, intrusion subscale of IES-R; PDEQ, Peritraumatic Dissociative Experiences Questionnaire; TAS-20, Twenty-Item Toronto Alexithymia Scale.

A second linear regression (stepwise method) was performed with peritraumatic dissociation as a dependent variable, and with both alexithymia and dissociation as independent variables. Data showed that a model composed of DIF, EOT, and DES-II explained $27.3 \%$ of the PDEQ score variance (Table 3).

\section{Discussion}

Our study confirmed that peritraumatic dissociation is a significant predictor of PTS. In accordance with literature, ${ }^{12}$ pathological effects of dissociative reaction during a traumatic event seems to be significantly related to both dissociation and alexithymia. Specifically, DIF and dissociation are good predictors of peritraumatic dissociation, whereas EOT was a moderate predictor. We agree with those who consider the therapeutic implications of the association between alexithymia and PTS to be relevant. However, we believe that this association has to be focused on the first factor of the TAS-20: DIF. In fact, according to some authors, ${ }^{13-15}$ this alexithymic factor represents the core difficulty in modulating affects. Moreover, in accordance with the literature about relation between alexithymia and dissociation, we believe that a traumatic event may cause a pathological reaction in individuals with a preexistent tendency to use the dissociation

Table 3 Summary of the linear regression analyses predicting PDEQ

\begin{tabular}{llllll}
\hline Variable & $\mathbf{B}$ & $\mathbf{S E}$ & $\boldsymbol{\beta}$ & $\boldsymbol{t}$ & $\boldsymbol{P}$ \\
\hline DIF & 0.328 & $0.08 \mathrm{I}$ & 0.266 & 4.04 & 0.000 \\
DES-II & 0.112 & 0.025 & 0.252 & 4.51 & 0.000 \\
EOT & 0.259 & 0.101 & 0.157 & 2.56 & 0.01 I \\
Adjusted $R^{2}=0.273$ & & & & \\
\hline
\end{tabular}

Abbreviations: B, beta unstandardized coefficient; DES-II, Dissociative Experiences Scale II; DIF, difficulty identifying feelings; EOT, externally oriented thinking; PDEQ, Peritraumatic Dissociative Experiences Questionnaire; SE, standard error. in a maladaptive way. From this point of view, we agree with those who consider alexithymia, and DIF, as a manifestation of dissociation of affects. Thus, we might suppose that, in our sample, peritraumatic dissociation is a maladaptive defense mechanism to modulate dissociated emotions. ${ }^{16}$

Limitations of our study include its correlational design and the use of only self-report measures. Future research should use clinical interviews to gather additional information on the psychopathological dimensions related to PTS symptoms.

\section{Disclosure}

The authors report no conflicts of interest in this work.

\section{References}

1. Lensvelt-Mulders G, van der Hart O, van Ochten JM, van Son MJM, Steele K, Breeman L. Relations among peritraumatic dissociations and posttraumatic stress: A meta-analysis. Clin Psychol Rev. 2008;28:1138-1151.

2. Murray J, Ehlers A, Mayou RA. Dissociation and post-traumatic stress disorders: two prospective studies of road traffic accident survivors. Br J Psychiatry. 2002;180:363-368.

3. Yehuda R, Steiner A, Kahana B, et al. Alexithymia in Holocaust survivors with and without PTSD. J Trauma Stress. 1997;10:93-100.

4. Badura AS. Theoretical and empirical exploration of the similarities between emotional numbing in posttraumatic stress disorder and alexithymia. J Anxiety Disord. 2003;17:349-360.

5. Monson CM, Price JL, Rodriguez BF, Ripley MP, Warner RA. Emotional deficits in military-related PTSD: an investigation of content and process disturbances. J Trauma Stress. 2004;17(3):275-279.

6. Carlson EB, Putnam FW. An update on the dissociative experiences scale. Dissociation. 1993;6:16-27.

7. Bagby RM, Parker JD, Taylor GJ. The twenty-item Toronto Alexithymia Scale - I. Item selection and cross-validation of the factor structure. J Psychosom Res. 1994;38(1):23-32.

8. Bressi C, Taylor G, Parker J, et al. Cross validation of the factor structure of the 20-item Toronto Alexithymia Scale: An Italian multicenter study. J Psychosom Res. 1996;41:551-559.

9. Weiss DS, Marmar CR. The impact of event scale - revised. In: Wilson JP, Keane TM, editors. Assessing Psychological Trauma and PTSD. New York: Guilford Press; 1997:399-411.

10. Craparo G, Faraci P, Rotondo G, Gori A. The impact of Event Scale Revised: psychometric properties of the Italian version in a sample of flood victims. Neuropsychiatr Dis Treat. 2013;9:1427-1432. 
11. Marmar CR, Weiss DS, Metzler TJ (1997). The peritraumatic dissociative experiences questionnaire. In: Wilson JP, Keane TM (Eds.). Assessing Psychological Trauma and PTSD. New York: Guilford Press; 1997:412-428.

12. Craparo G. [Posttraumatic stress disorder]. Rome: Carocci; 2013. Italian.

13. Benoit M, Bouthillier D, Moss E, Rousseau C, Brunet A. Emotion regulation strategies as mediators of the association between level of attachment security and PTSD symptoms following trauma in adulthood. Anxiety Stress Coping. 2010;23:101-118.
14. Frewen PA, Dozois DJ, Neufeld RW, Lanius RA. Meta-analysis of alexithymia in posttraumatic stress disorder. J Trauma Stress. 2008;21: 243-246.

15. Craparo G, Gori A, Petruccelli I, Cannella V, Simonelli C. Intimate partner violence: relationship between alexithymia, depression, attachment styles, and coping strategies of battered women. J Sex Med. 2014;11(6): 1484-1494.

16. Craparo G. The role of dissociation, affect dysregulation, and developmental trauma in sexual addiction. Clin Neuropsychiatry. 2014;11(2): 86-90.

\section{Publish your work in this journal}

Neuropsychiatric Disease and Treatment is an international, peerreviewed journal of clinical therapeutics and pharmacology focusing on concise rapid reporting of clinical or pre-clinical studies on a range of neuropsychiatric and neurological disorders. This journal is indexed on PubMed Central, the 'PsycINFO' database and CAS, and is the official journal of The International Neuropsychiatric Association (INA). The manuscript management system is completely online and includes a very quick and fair peer-review system, which is all easy to use. Visit http://www.dovepress.com/testimonials.php to read real quotes from published authors. 